\title{
Synthesis and Characterization of Sulfamic Acid-
} Functionalized Nanoparticles and Study of Its Catalytic Activity for the Oxidation of Sulfides to Sulfoxides

\author{
Arash Ghorbani-Choghamarani,* Gouhar Azadi
}

Department of Chemistry, Faculty of Science, Ilam University, Ilam, Iran

* Corresponding author's e-mail address: arashghch58@yahoo.com

RECEIVED: October 23, 2015 * REVISED: February 6, 2016 * ACCEPTED: February 11, 2016

Abstract: The synthesis, characterization and applications of sulfamic acid-functionalized magnetic nanoparticles as a magnetically separable nanocatalyst are described. The nanostructure of the catalyst was characterized by FT-IR spectroscopy, thermogravimetric (TGA) analysis, powder X-ray diffraction (XRD), scanning electron microscopy (SEM) and transmission electron microscope (TEM).

Keywords: piperidine-4-carboxylic acid, $\mathrm{Fe}_{3} \mathrm{O}_{4}-\mathrm{SA}-\mathrm{PPCA}$, magnetic nanoparticles, recyclability.

\section{INTRODUCTION}

$\mathbf{H}$ eterogeneous catalysts have been extensively employed in various fields because they have fewer of the drawbacks of homogeneous catalysts, such as the difficulties in recovery and regeneration. [1] Magnetic nanoparticles are efficient, readily available, high-surfacearea resulting in high catalyst loading capacity and outstanding stability heterogeneous supports for catalysts. ${ }^{[2]}$ Magnetic nanoparticles (MNPs) have recently appeared as a new type of catalyst support because of their easy preparation and functionalization, facile recovery and recyclability via magnetic force as well as low toxicity and price. ${ }^{[3]}$ Thus, waste and costs can be greatly reduced. Among the various magnetic nanoparticles as the core magnetic support, $\mathrm{Fe}_{3} \mathrm{O}_{4}$ nanoparticles are arguably the most extensively studied. ${ }^{[4-6]}$

Sulfuric acid functionalized magnetite nanoparticles as recyclable strong solid acid catalyst open up new avenue to introduce an amazing and efficient system for facilitating catalyst recovery in different organic reactions. Sulfonic acid groups have been covalently bonded to these supports by various methods such as, oxidation of attached thiols, hydrolysis of sulfonic acid chlorides, sulfonation of supported phenyl groups, and immobilization of perfluorosulfonic acid triethoxysilanes. ${ }^{[7-11]}$ This catalyst allows the combination of well-known procedures for catalyst heterogenization with techniques for magnetic separation. ${ }^{[12,13]}$

Organic sulfoxides are useful and active intermediates in both laboratory and industry, organic synthesis and therefore the chemoselective oxidation of organic sulfides to the corresponding sulfoxides has been the subject of various studies for the past two decades. ${ }^{[14]}$ Although a wide variety of reagent and catalytic systems are available for this key transformation, ${ }^{[15-22]}$ the major disadvantages of these methods include removal or recovery of the expensive catalyst, the formation of large amounts of toxic waste, overoxidation of sulfoxides to sulfones and long reaction time, hence an environmentally benign process and develop new catalysts remains in great demand to overcome these drawbacks.

\section{EXPERIMENTAL}

The reagents and solvents used in this work were all purchased from Aldrich and Merck and used without further purification. Powder X-ray diffraction (XRD) analysis was conducted on Rigaku-Dmax 2500 diffractometer with nickel filtered $\mathrm{Cu}-K_{\alpha}$ radiation $(\lambda=1.5418 \AA$, $40 \mathrm{kV})$. The particle 
size and morphology were investigated by a JEOL JEM-2010 scanning electron microscopy (SEM), on an accelerating voltage of $200 \mathrm{kV}$. Transmission electron microscopy (TEM) analysis was performed using a Zeiss-EM10C TEM. Supermagnetic properties of the catalyst were measured on Vibrating Sample Magnetometer (VSM) MDKFD.

\section{Preparation of Sulfamic Acid- Functionalized Magnetic $\mathrm{Fe}_{3} \mathrm{O}_{4}$ Nanoparticles ( $\mathrm{Fe}_{3} \mathrm{O}_{4}$-SA-PPCA)}

Sulfamic acid-functionalized magnetic $\mathrm{Fe}_{3} \mathrm{O}_{4}$ nanoparticles ( $\mathrm{Fe}_{3} \mathrm{O}_{4}$-SA-PPCA) was prepared by the route outlined in Scheme 1. Magnetic $\mathrm{Fe}_{3} \mathrm{O}_{4}$-PPCA nanoparticles was prepared through chemical coprecipitation method. In this procedure the stoichiometric amount of $\mathrm{Fe}(\mathrm{III}), \mathrm{Fe}$ (II) salts and piperidine-4-carboxylic acid in the molar ratio $2 \mathrm{Fe}(\mathrm{III})$ : 1Fe(II) : 4PPCA was dissolved in $100 \mathrm{~mL}$ deionized water and then solution was kept at a constant temperature of $60^{\circ} \mathrm{C}$ for 15 minutes under vigorous stirring. Subsequently, solution of ammonium hydroxide was added until the $\mathrm{pH}$ was raised to 11 at which a black suspension was formed. This suspension was then refluxed at $80^{\circ} \mathrm{C}$ for $6 \mathrm{~h}$ with vigorous stirring. $\mathrm{Fe}_{3} \mathrm{O}_{4}-\mathrm{PPCA}$ nanoparticle was separated from the aqueous solution by magnetic decantation, washed with distilled water several times and then dried in an oven overnight. Whole synthesis was done under $\mathrm{N}_{2}$ atmosphere. Ultimately, the synthesized PPCA-MNPs (500 mg) were dispersed in dry $\mathrm{CH}_{2} \mathrm{Cl}_{2}(5 \mathrm{~mL}$ ) by ultrasonic bath for $15 \mathrm{~min}$. Subsequently, chlorosulfonic acid (1 mL) was added dropwise over a period of $30 \mathrm{~min}$ at room temperature. Hydrogen chloride gas evolved from the reaction vessel immediately. The mixture was mechanically stirred for $3 \mathrm{~h}$ until $\mathrm{HCl}$ gas evolution was stopped. The resulted magnetic nanoparticles were separated by an

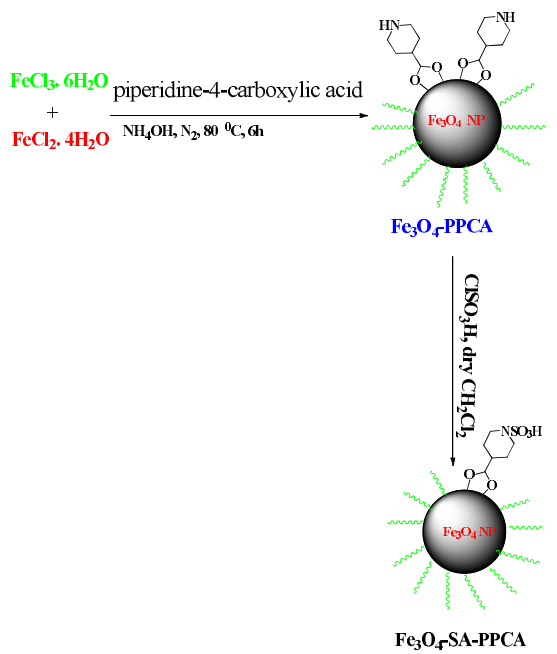

Scheme 1. Synthesis of sulfamic acid-functionalized nanoparticles. external magnet device and washed three times with dry $\mathrm{CH}_{2} \mathrm{Cl}_{2}$ and ethanol to remove the unattached substrates.

\section{General Procedure for the Oxidation of Sulfides to Sulfoxides}

$\mathrm{Fe}_{3} \mathrm{O}_{4}$-SA-PPCA (0.04 g) was added to a mixture of sulfide (1 mmol) and $\mathrm{H}_{2} \mathrm{O}_{2}(0.5 \mathrm{~mL})$ in $\mathrm{EtOH}$ at $60^{\circ} \mathrm{C}$ and the mixture was stirred for the appropriate time. The progress was monitored by TLC. After completion of the reaction, the catalyst was separated by an external magnet and the combined organics were washed with water $(5 \mathrm{~mL})$ and dried over anhydrous $\mathrm{Na}_{2} \mathrm{SO}_{4}$. The evaporation of solvent under reduced pressure gave the pure products in excellent yields.

\section{RESULTS AND DISCUSSION}

In the present work, we report our results about $\mathrm{Fe}_{3} \mathrm{O}_{4}-\mathrm{SA}$ PPCA as a recoverable heterogeneous catalyst for selective oxidation of sulfides to sulfoxides in the presence of $33 \%$ $\mathrm{H}_{2} \mathrm{O}_{2}$.

Successful functionalization of the MNPs can be inferred from FT-IR techniques (Figure 1). The Fe-O stretching vibration near $575 \mathrm{~cm}^{-1}$ was observed and $\mathrm{O}-\mathrm{H}$ stretching vibration near $3500 \mathrm{~cm}^{-1}$. In the spectrum of $\mathrm{Fe}_{3} \mathrm{O}_{4}-\mathrm{PPCA}$ the peak at $3423 \mathrm{~cm}^{-1}$ was probably attributed to the $\mathrm{NH}$ groups, which is overlapped by the $\mathrm{O}-\mathrm{H}$ stretching vibration. The presence of the anchored PPCA group is confirmed by $\mathrm{C}-\mathrm{H}$ stretching vibrations that appear at 2918 and $2846 \mathrm{~cm}^{-1}$ in $\mathrm{Fe}_{3} \mathrm{O}_{4}-\mathrm{PPCA}$ spectra.

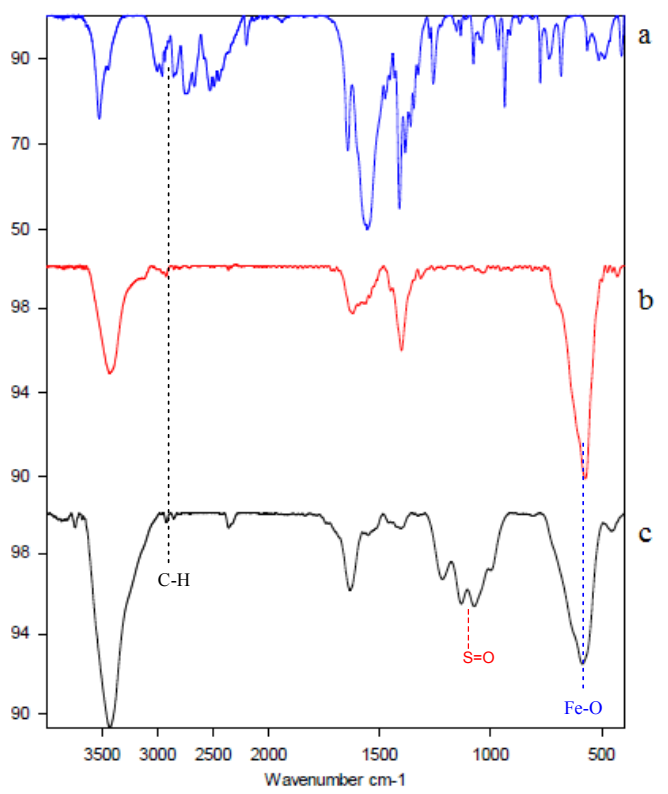

Figure 1. The comparative FT-IR spectra for (a) pure PPCA; (b) $\mathrm{Fe}_{3} \mathrm{O}_{4}$-PPCA; and (c) $\mathrm{Fe}_{3} \mathrm{O}_{4}-\mathrm{SA}$-PPCA. Synthesis of sulfamic acid-functionalized nanoparticles. 
Furthermore, it has been reported that the wavenumber separation between the $\mathrm{COO}^{-}$as and $\mathrm{COO}^{-}$IR bands can be used to distinguish the type of the interaction. ${ }^{[23]}$ Since the wavenumber separation between the $\mathrm{COO}^{-}$as and $\mathrm{COO}^{-}{ }_{\mathrm{s}}$ bands is $172 \mathrm{~cm}^{-1}\left(1595-1423=172 \mathrm{~cm}^{-1}\right)$, it can be concluded that the interaction between the $\mathrm{COO}^{-}$group and the Fe atom is covalent and bridging bidentate. These results provided the evidences that the piperidine-4carboxylic acid groups were successfully attached to the surface of $\mathrm{Fe}_{3} \mathrm{O}_{4}$ nanoparticles as a carboxylate. Reaction of PPCA- $\mathrm{Fe}_{3} \mathrm{O}_{4}$ with chlorosulfonic acid produces SA-PPCAMNPs in which the presence of sulfonylmoiety is asserted with 1216 and $1132 \mathrm{~cm}^{-1}$ bands in FT-IR spectra. Moreover, the peak at $1111 \mathrm{~cm}^{-1}$ belonged to $\mathrm{S}=0$ stretching vibrations in the sulfamic functional groups. These results were in agreement with the chemical component of the materials prepared.

Thermal analysis combining thermogravimetric analysis (TGA) and differential thermal analysis (DTA) of the $\mathrm{Fe}_{3} \mathrm{O}_{4}$-SA-PPCA show the mass loss of the organic materials as they decompose upon heating (Figure 2). There is a mass weight loss of $7.2 \%$ between 250 and $465{ }^{\circ} \mathrm{C}$ related to the breakdown of the PPCA-SA moieties.

The XRD spectrum of the catalyst is shown in Figure 3. The positions and relative intensities of all peaks match

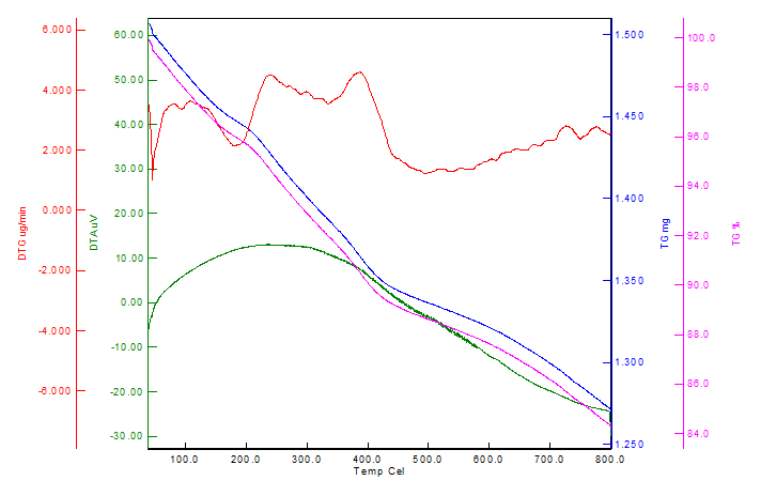

Figure 2. TGA and DTA thermograms o $\mathrm{Fe}_{3} \mathrm{O}_{4}$-SA-PPCA.

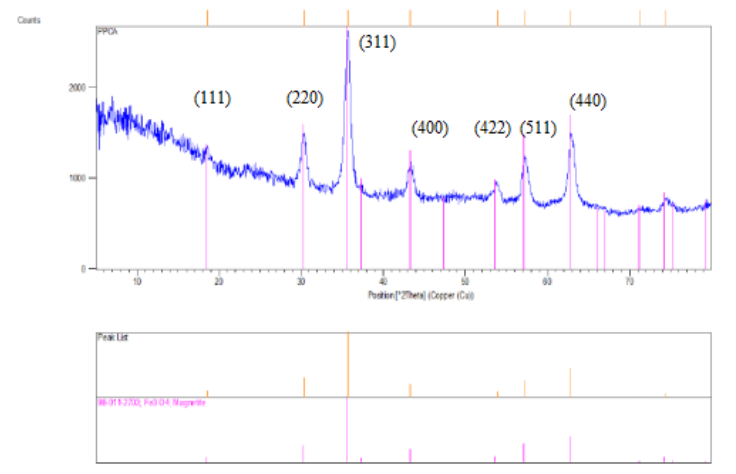

Figure 3. XRD pattern of $\mathrm{Fe}_{3} \mathrm{O}_{4}-\mathrm{SA}-\mathrm{PPCA}$.

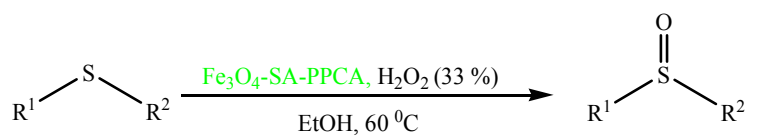

$\mathrm{R}^{1}, \mathrm{R}^{2}=$ Aryl, Heterocyclic, Benzylic and Alkyl

Scheme 2. TEM micrographs of $\mathrm{Fe}_{3} \mathrm{O}_{4}$-SA-PPCA.

well with reported $\mathrm{XRD}$ of $\mathrm{Fe}_{3} \mathrm{O}_{4}$ (magnetite). It implies that the spinal structure of $\mathrm{Fe}_{3} \mathrm{O}_{4}$ has been retained during the process of catalyst preparation.

Figure 4 shows TEM micrographs of synthesized catalyst $\left(\mathrm{Fe}_{3} \mathrm{O}_{4}\right.$-SA-PPCA). It can be seen that most of the particles were monodispersed and uniform with a spherical shape.

After full characterization of synthesized catalyst and in continuation of our studies on environmentally benign chemical processes, ${ }^{[24-27]}$ in the present work we disclose that $\mathrm{Fe}_{3} \mathrm{O}_{4}$-SA-PPCA can be used as a new heterogeneous catalyst for the selective oxidation of structurally diverse sulfides to sulfoxides using $33 \% \mathrm{H}_{2} \mathrm{O}_{2}$ in ethanol as solvent at $60{ }^{\circ} \mathrm{C}$ (Scheme 2).

In order to optimize the reaction conditions and test the activity of catalyst, we examined the oxidation reaction of dibenzyl sulfide as a model compound using $33 \% \mathrm{H}_{2} \mathrm{O}_{2}$ under various reaction conditions in terms of time and product yield (Table 1).
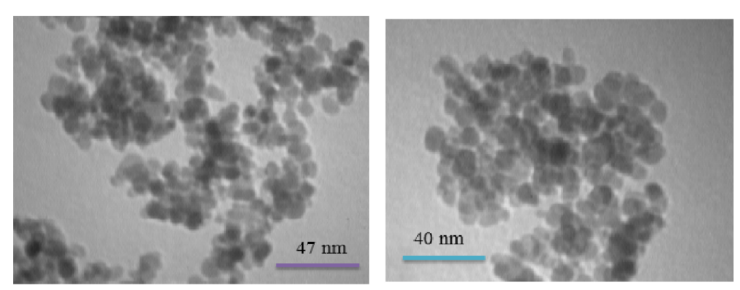

Figure 4. TEM micrographs of $\mathrm{Fe}_{3} \mathrm{O}_{4}$-SA-PPCA.

Table 1. Optimization of the reaction conditions for the selective oxidation of dibenzyl sulfide(a) to dibenzyl sulfoxide.

\begin{tabular}{ccccc}
\hline Entry & Catalyst $/ \mathrm{mg}$ & Time $/ \mathrm{min}$ & Temp. $/{ }^{\circ} \mathrm{C}$ & Yield $/ \%$ \\
\hline 1 & 0.00 & 65 & 60 & 31 \\
2 & 0.01 & 65 & 60 & 56 \\
3 & 0.02 & 65 & 60 & 57 \\
4 & 0.03 & 65 & 60 & 91 \\
5 & 0.04 & 65 & 60 & 98 \\
6 & 0.05 & 65 & 60 & 98 \\
7 & 0.04 & 65 & 50 & 41 \\
8 & 0.04 & 65 & 40 & 35 \\
\hline
\end{tabular}

(a) Dibenzyl sulfide (1 mmol), $\mathrm{H}_{2} \mathrm{O}_{2}(0.5 \mathrm{~mL})$, MNPs-SA-PPCA (0.04 g). 
As seen in Table 1, no significant amount of sulfoxide was produced in the absence of catalyst and this indicated the requirement of a catalyst for this reaction also yield was raised as the amount of catalyst was increased (Figure 5).

The results show (Table 1) that the optimize conditions for the complete conversion of dibenzyl sulfide to dibenzyl sulfoxide are in the presence of $33 \% \mathrm{H}_{2} \mathrm{O}_{2}(0.5 \mathrm{~mL})$ and $\mathrm{Fe}_{3} \mathrm{O}_{4}$-SA-PPCA as catalyst $(0.04 \mathrm{~g})$ in ethanol at $60^{\circ} \mathrm{C}$.

To demonstrate generality and efficiency of the method, different aromatic, liner, benzylic and heterocyclic sulfides were oxidizes under optimized reaction condition (Table 2).

As can be seen from Table 2, the catalytic system worked exceedingly well in the oxidation of sulfides with wide range of substrates. The expected products were obtained in short time and in high yields.

To show the chemoselectivity of the presented protocol, the sulfides containing acid-sensitive functional groups was subjected to the sulfoxidation reaction. This functional group remained intact during the conversion of sulfide to sulfoxides (Table 2, entries 7,11 ).

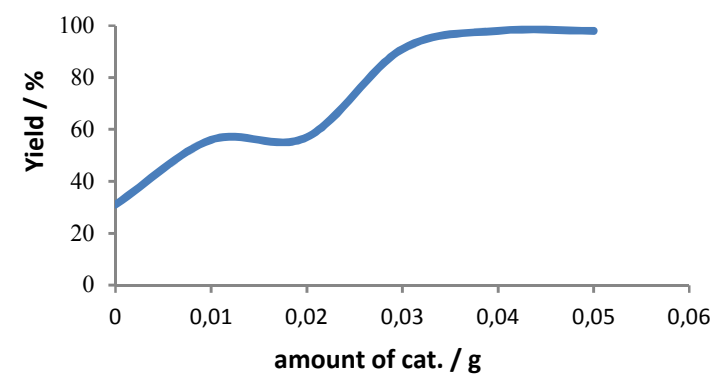

Figure 5. Effect of different amount of catalyst on the oxidation of sulfides to sulfoxides.
For practical purposes, the reusability of the catalysts is highly desirable. Thus the recovery and reusability of $\mathrm{Fe}_{3} \mathrm{O}_{4}$-SA-PPCA were investigated in the oxidation reaction. In these experiments, the reaction mixture was dilute with ethanol and the catalyst was easily and rapidly separated from the product by exposure to an external magnet and decantation of the reaction solution. The remaining magnetic nanocatalyst was further washed with $\mathrm{CH}_{2} \mathrm{Cl}_{2}$ to remove residual product. Then, the reaction vessel was charged with fresh substrate and subjected to the next. As shown in Figure 6 the catalyst was reused up to 10 runs and no significant loss of activity was observed.

On the basis of the literature available for sulfoxidation using hydrogen peroxide in the presence of an acid catalyst, we propose the following mechanism as shown in Scheme 1. Explanation for this process is in situ formation of peroxyacid by the reaction of $\mathrm{Fe}_{3} \mathrm{O}_{4}$-SA-PPCA with hydrogen peroxide In the first step, and then, oxygen transfer to the organic substrate (Scheme 3).

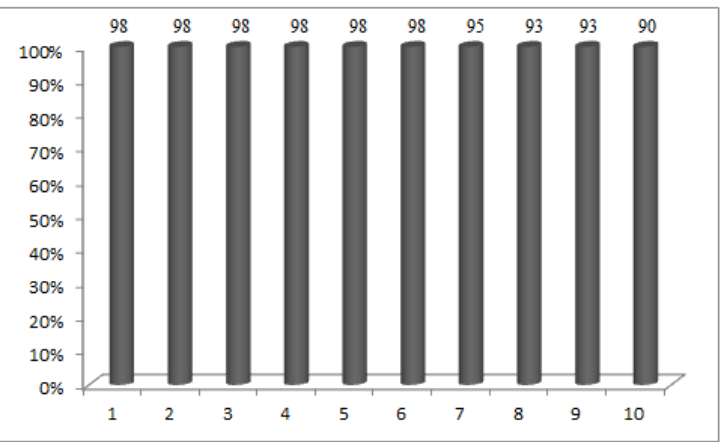

Figure 6. Catalyst reusability in the oxidation of dipropyl sulfide using $\mathrm{H}_{2} \mathrm{O}_{2}(0.5 \mathrm{~mL})$ at $60^{\circ} \mathrm{C}$.
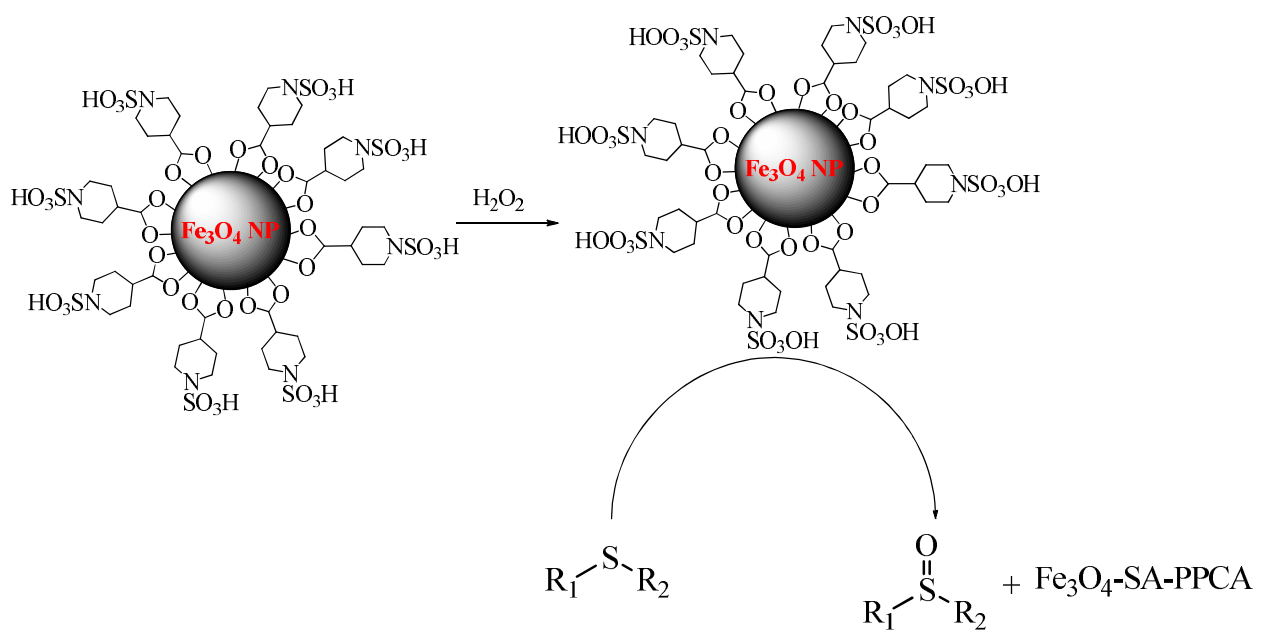

Scheme 3. Proposed mechanism for the sulfide oxidation with $\mathrm{H}_{2} \mathrm{O}_{2}$ in the presence of $\mathrm{Fe}_{3} \mathrm{O}_{4}-\mathrm{SA}$-PPCA. 
Table 2. Oxidation of sulfides to sulfoxides catalyzed by MNPs-SA-PPCA(a).

\begin{tabular}{|c|c|c|c|c|c|}
\hline Entry & Substrate & Product & Time / min & Yield $^{(b)} / \%$ & M.p found $/{ }^{\circ} \mathrm{C}$ \\
\hline 1 & & & 65 & 98 & $130-131^{[28]}$ \\
\hline 2 & & $O$ & 5 & 82 & $\mathrm{Oil}{ }^{[29]}$ \\
\hline 3 & & & 20 & 90 & Oil[30] \\
\hline 4 & & & 5 & 95 & Oil ${ }^{[28]}$ \\
\hline 5 & & & 80 & 97 & $32^{[28]}$ \\
\hline 6 & & & 30 & 90 & Oil ${ }^{[31]}$ \\
\hline 7 & & & 20 & 90 & Oil $\left.\right|^{[31]}$ \\
\hline 8 & & & 5 & 98 & Oil29] \\
\hline 9 & & & 85 & 96 & $127^{[28]}$ \\
\hline 10 & & & 45 & 95 & $87-89^{[32]}$ \\
\hline 11 & & & 30 & 90 & Oil ${ }^{[31]}$ \\
\hline
\end{tabular}

(a) Reaction condition: MNPs-SA-PPCA $(0.04 \mathrm{~g})$, sulfides $(1 \mathrm{mmol}), \mathrm{H}_{2} \mathrm{O}_{2}(0.5 \mathrm{~mL})$ in ethanol at $60^{\circ} \mathrm{C}$.

(b) Isolated yield.

\section{CONCLUSIONS}

In conclusion, a recyclable magnetic nanocatalyst is easily synthesized and characterized. $\mathrm{Fe}_{3} \mathrm{O}_{4}$-SA-PPCA can catalyze the oxidation of sulfides to sulfoxides. Simplicity of operation, high yields, stability, easy isolation of products, and excellent recyclability of the catalytic system are the attractive features of this methodology. This method may provide a way for fabricating new classes of magnetic materials and thus can be the potential material for various applications in the synthesis of organic compounds.

Acknowledgment. This work was supported by the research facilities of Ilam University, Ilam, Iran. 


\section{REFERENCES}

[1] S. Ko, J. Jang, Angew. Chem. Int. Ed. 2006, 45, 7564.

[2] A. Rostami, B. Tahmasbi, F. Abedi, Z. Shokri, J. Mol. Catal. A: Chem. 2013, 378, 200.

[3] J. Safari, Z. Zarnegar, Monatsh. Chem. 2013, 144, 389.

[4] R. B. Nasir Baig, R. S. Varma, Green Chem. 2013, 15, 398.

[5] R. B. Nasir Baig, R. S. Varma, Chem. Commun. 2013, 49, 752.

[6] M. B. Gawande, A. K. Rathi, P. S. Branco, R. S. Varma, Appl. Sci. 2013, 3, 656.

[7] W. M. Van Rhijn, D. E. De Vos, B. F. Sels, W. D. Bossaert, P. A. Jacobs, Chem. Commun. 1998, 317.

[8] J. A. Melero, G. D. Stucky, R. Grieken, G. Morales, J. Mater. Chem. 2002, 12, 1664.

[9] C. W. Jones, K. Tsuji, M. E. Davis, Microporous Mesoporous Mater. 1999, 33223.

[10] M. A. Harmer, Q. Sun, M. J. Michalczyk, Z. Y. Yang, Chem. Comm. 1997, 1803.

[11] M. B. Gawande, A. K. Rathi, I. D. Nogueira, R. S. Varma, P. S. Branco, Green Chem. 2013, 15, 1895.

[12] F. Nemati, R. Saeedirad, Chin. Chem. Lett. 2013, 24, 370.

[13] F. Nemati, M. M. Heravi, M. M. Saeedirad, R. Chin, J. Catal. 2012, 33, 1825.

[14] S. Rayati, F. Nejabat, S. Zakavi, Inorg. Chem. Commun. 2014, 40, 82.

[15] K. Sato, M. Hyodo, M. Aoki, X. Q. Zheng, R. Noyori, Tetrahedron 2001, 57, 2469.

[16] B. M. Choudary, B. Bharathi, C. V. Reddy, M. L. Kantam, J. Chem. Soc. Perkin Trans. 2002, 1, 2069.

[17] B. Li, A. H. Liu, L. N. He, Z. Z. Yang, J. Gao, K. H. Chen, Green Chem. 2012, 14, 130.
[18] M. Bagherzadeh, M. Zare, J. Sulfur Chem. 2011, 32, 335.

[19] M. M. Khodaei, K. Bahrami, J. Sulfur Chem. 2010, 31, 83.

[20] Y. Hu, X. B. Liu, D. Fang, Catal. Sci. Technol. 2014, 4(1), 38.

[21] M. Masteri-Farahani, S. Abednatanzi, Inorg. Chem. Commun. 2013, 49, 39.

[22] B. Li, A. Liu, L. He, Z. Z. Yang, J. Gao, K. H. Chen, Green Chem. 2012, 14, 130.

[23] F. Zamani, S. Kianpour, Catal. Commun. 2011, 45, 1.

[24] A. Ghorbani-Choghamarani, G. Azadi, J. Iran. Chem. Soc. 2011, 8, 1082.

[25] A. Ghorbani-Choghamarani, M. Hajjami, H. Goudarziafshar, M. Nikoorazm, S. Mallakpour, F. Sadeghizadeh, G. Azadi, Monatsh Chem. 2009, 140, 607.

[26] M. A. Zolfigol, K. Amani, M. Hajjami, A. GhorbaniChoghamarani, Monatsh Chem. 2008, 139, 895.

[27] A. Ghorbani-Choghamarani, G. Azadi, RSC Adv. 2015, 5, 9752.

[28] D. Y. Dai, L. Wang, Q. Chen, M. Y. He, J. Chem. Res. 2014, 38, 183.

[29] A. Shaabani, A. H. Rezayan, Catal. Commun. 2007, 8, 1112.

[30] F. R. Bisogno, A. Rioz-Martnez, C. Rodguez, I. Lavandera, G. de Gonzalo, D. E. Torres PazmiCo, M. W. Fraaije, V. Gotor, Chem. Cat. Chem. 2010, 2, 946.

[31] A. Ghorbani-Choghamarani, H. Goudarziafshar, M. Nikoorazm, S. Yousefi, Lett. Org. Chem. 2009, 6, 335.

[32] S. P. Sharma, M. V. S. Suryanarayana, A. K. Nigam, A. S. Chauhan, L. N. S. Tomar, Catal. Commun. 2009, 10, 905. 